\title{
Microbubble Phenomenon in the Grease Lubricating Film Induced by Micro-Oscillation
}

\author{
Shuhai Liu · Dan Guo - Guoxin Xie
}

Received: 31 January 2013/Accepted: 7 May 2013/Published online: 24 May 2013

(c) The Author(s) 2013. This article is published with open access at Springerlink.com

\begin{abstract}
A microbubble phenomenon induced by microoscillation in the grease lubricating film confined within a nanogap between a highly polished steel ball and a smooth glass disc has been observed with an interferometer. Experimental results show that when the micro-oscillation frequency is a constant value, the microbubble number increases with the micro-oscillation amplitude. When the micro-oscillation amplitude is a constant value, the microbubble number increases with the micro-oscillation frequency when the latter is lower than the critical value and decreases with the micro-oscillation frequency when it is higher than the critical value. Theoretical models and analyses have been used to discuss the bubble formation and describe the characteristics of bubble movement.
\end{abstract}

Keywords Grease $\cdot$ micro-oscillation $\cdot$ Microbubble

\section{Introduction}

Reciprocating engineering components, such as rolling or sliding element bearings, cams, and gears, are used in a wide range of industries. Wear occurs easily when two contacting bodies are subject to micro-oscillatory relative motion (the amplitude is close to the diameter of the Hertzian contact area). Consequently, grease is widely used

\footnotetext{
S. Liu $(\bowtie)$

School of Mechanical and Transportation Engineering, China University of Petroleum, Beijing 102200, People's Republic of China

e-mail: liu_shu_hai@163.com

D. Guo - G. Xie

State Key Laboratory of Tribology, Tsinghua University, Beijing 100084, People's Republic of China
}

as a lubricant in reciprocating engineering components. Lubricating grease is a two-phase system that consists of base oil, either mineral or synthetic, and a thickener. The primary role of the grease lubricant is to form and maintain a lubricating film between two moving surfaces. A significant body of experimental and theoretical work has so far been conducted on understanding the underlying mechanisms and exploring the relevant applications of grease lubrication [1-4]. The results of such studies have led to many different views on grease lubricant [5-14]. Cann and colleagues $[5,6]$ investigated grease lubrication under fully flooded and lubricant-starved conditions under a rolling contact using a ball-on-plate optical interferometry. In subsequent studies, [7-9] they used infrared reflection spectroscopy and determined that the grease aged as thin films on metal surfaces and degraded in a bearing simulation device . Larsson et al. [10] traced individual grease thickener particles (lumps) as they passed through the elastohydrodynamics lubrication contact using a ballon-plate optical interferometry under pure rolling motion. Miettinen et al. clarified how contaminants in the grease [11] and running parts [12] influence the acoustic emission (AE) of the rolling bearing based on measurements of the AE. Mota and Ferreira [13] investigated the influence of grease composition on wear using a twin-disc machine under pure rolling conditions, and Cousseau et al. [14] compared three different lubricating greases and their bleed and base oils using ball-on-plate optical interferometry.

Although grease lubrication has been studied for decades both theoretically and experimentally, most of the work has been carried out under steady-state conditions, and grease lubrication under non-steady state conditions has received relatively little attention. Li et al. [15] recently presented a detailed review of lubrication under non-steady state conditions, but most of the studies reviewed were 
carried out for liquid oils. Li et al. [15, 16] investigated the lubricating behavior of grease lubricant films under nonsteady state conditions, including swaying motions (acceleration/deceleration) and micro-oscillation, using ball-on-plate optical interferometry based on the technique of relative optical interference intensity. Experimental results of such studies indicate that grease lubrication under non-steady state conditions is very complex, and the characteristics of grease lubricant under these conditions are as yet far less well understood as those under steadystate conditions. Hence, more theoretical and experimental study is required to reveal the characteristics of grease lubrication under non-steady state conditions.

Here we present the results of our study on the effects of amplitude and frequency on the lubricating behavior of grease lubricating film induced by micro-oscillation using interferometry. Our aim was to provide some guidance by which to predict the failure of grease lubricating film in the presence of a micro-oscillation.

\section{Experimental Conditions}

The experimental configuration is shown in Fig. 1a. The contacting pairs are composed of a precision 7/8-inchdiameter steel ball (Young's modulus $E=210 \mathrm{GPa}$, Poisson's ratio $v=0.3)$ and a glass disk $(E=77.6 \mathrm{GPa}$, $v=0.17)$. A monochromatic light with a wavelength of $600 \mathrm{~nm}$ was used as the light source. When the beam of the light reaches the upper surface of the $\mathrm{Cr}$ layer, it is split into two beams: one is reflected at the upper surface of the $\mathrm{Cr}$ layer, and the other passes through the $\mathrm{Cr}$ layer and the lubricant film and is then reflected at the surface of the steel ball. The state of the contact region was captured with a microscope and a charge coupled device (CCD) camera, and real-time interference fringes were ultimately monitored on the computer.

For the micro-oscillation condition, the glass disk was fixed, the steel ball was driven by the vibration exciter, and pure sliding between the contact surfaces occurred. A schematic diagram of the micro-oscillation is shown in Fig. 1b, where $\mathrm{L}$ is the amplitude, which represents the moving distance of the contact area. The grease used in this investigation has a synthetic base oil with a lithium complex thickener whose characteristics are summarized in Table 1. The glass disc and pieces of the apparatus coming in contact with the test solution were cleaned carefully with xylene, isopropanol, and acetone. The load was $14 \mathrm{~N}$, providing a maximum Hertzian pressure of $0.42 \mathrm{GPa}$ and a contact diameter of $250 \mu \mathrm{m}$. The experiment was performed at a temperature of $25 \pm 1{ }^{\circ} \mathrm{C}$ and the test time was $5 \mathrm{~min}$. (a)
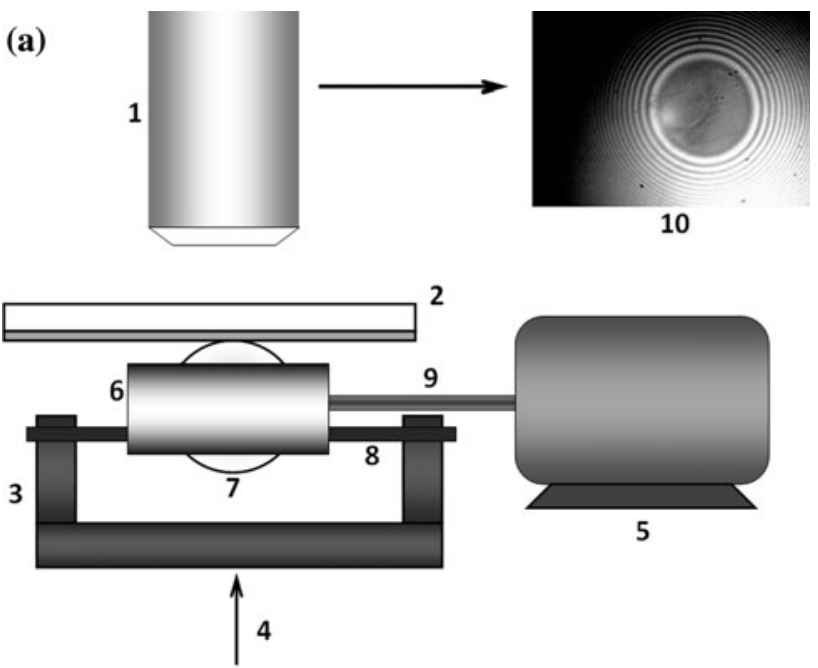

(b)

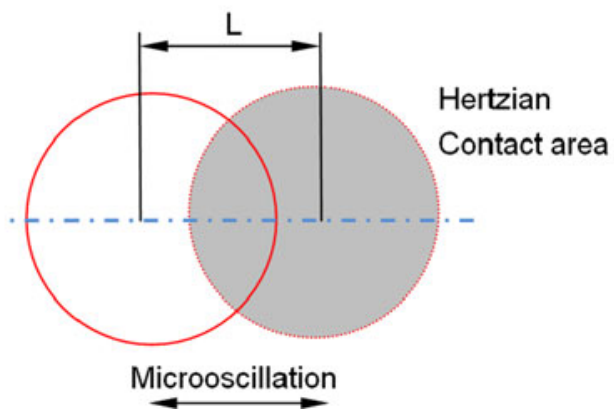

Fig. 1 a Schematic of experimental set-up: 1 microscope, 2 glass disk, 3 pedestal, 4 loading system, 5 vibration exciter, 6 clamping device, 7 steel ball, 8 sliding, 9 connector, 10 computer-coupled device (CCD) image. b Schematic diagram of the micro-oscillation. $L$ Amplitude

Table 1 Grease lubricant characteristics

\begin{tabular}{ll}
\hline Grease lubricant & Characteristics \\
\hline Soap type & Lithium \\
Base oil viscosity at $25^{\circ} \mathrm{C}(\mathrm{cSt})$ & 150 \\
Dropping point $\left({ }^{\circ} \mathrm{C}\right)$ & 180 \\
\hline
\end{tabular}

\section{Experimental Results}

\subsection{Microbubble Phenomenon Induced} by Micro-Oscillation

Interference patterns of the grease lubricating film under different micro-oscillation amplitudes are shown in Fig. 2. The real-time interference patterns of the grease lubricating film in the absence of any micro-oscillation are shown in Fig. 2a-1-a-4. The central dark region surrounded by the white circle is the Hertz contact region where under the load of $14 \mathrm{~N}$ the film thickness is $100 \mathrm{~nm}$ and the radius of the contract region is $250 \mu \mathrm{m}$. When the micro-oscillation 
amplitude was increased, the contact region can be seen to acquire the overlapping interference pattern (Fig. 2b-1-b4 ) due to the contact region moving. The micro-oscillation amplitude $(50 \mu \mathrm{m})$ can be measured from the distance between the regions surrounded by the red circles in Fig. 2b-3. As the micro-oscillation amplitude was increased from 50 to $150 \mu \mathrm{m}$, no obvious change in the outlet region could be observed (Fig. 2c-1-c-4). However, when the micro-oscillation amplitude was increased yet further to $200 \mu \mathrm{m}$, many either spherical or ellipsoidal microbubbles appeared around the edge of the central region (Fig. 2d-1-d-4). These bubbles, which were approximately few micrometers in diameter, emerged at the leading and trailing edges of both the grease lubricated contacts one after another and then moved off the central region roughly in a radial direction. As micro-oscillation behavior is determined by amplitude and frequency, we then examined the effect of micro-oscillation amplitude and frequency on microbubble behavior.

\subsection{Effect of Micro-Oscillation Amplitude on Microbubble Behavior}

To investigate the effect of micro-oscillation amplitude on microbubble behavior in detail, we varied the microoscillation amplitude while maintaining micro-oscillation frequency at $50 \mathrm{~Hz}$. The interference patterns of the grease lubricating film under different micro-oscillation amplitudes are shown in Fig. 3, where the arrow indicates the direction of the sliding micro-oscillation. When the microoscillation amplitude was $\leq 10 \mu \mathrm{m}$, the microbubbles became too small to be distinguished from each other (Fig. 3a). As the micro-oscillation amplitude was increased, the size of the area where microbubbles emerged also increased (Fig. 3b-d) and the microbubbles moved more quickly. When the micro-oscillation amplitude was increased to $50 \mu \mathrm{m}$ (Fig. 3b) and $110 \mu \mathrm{m}$ (Fig. 3c), there was still an abundant number of microbubble trajectories; this trend became even more obvious when the
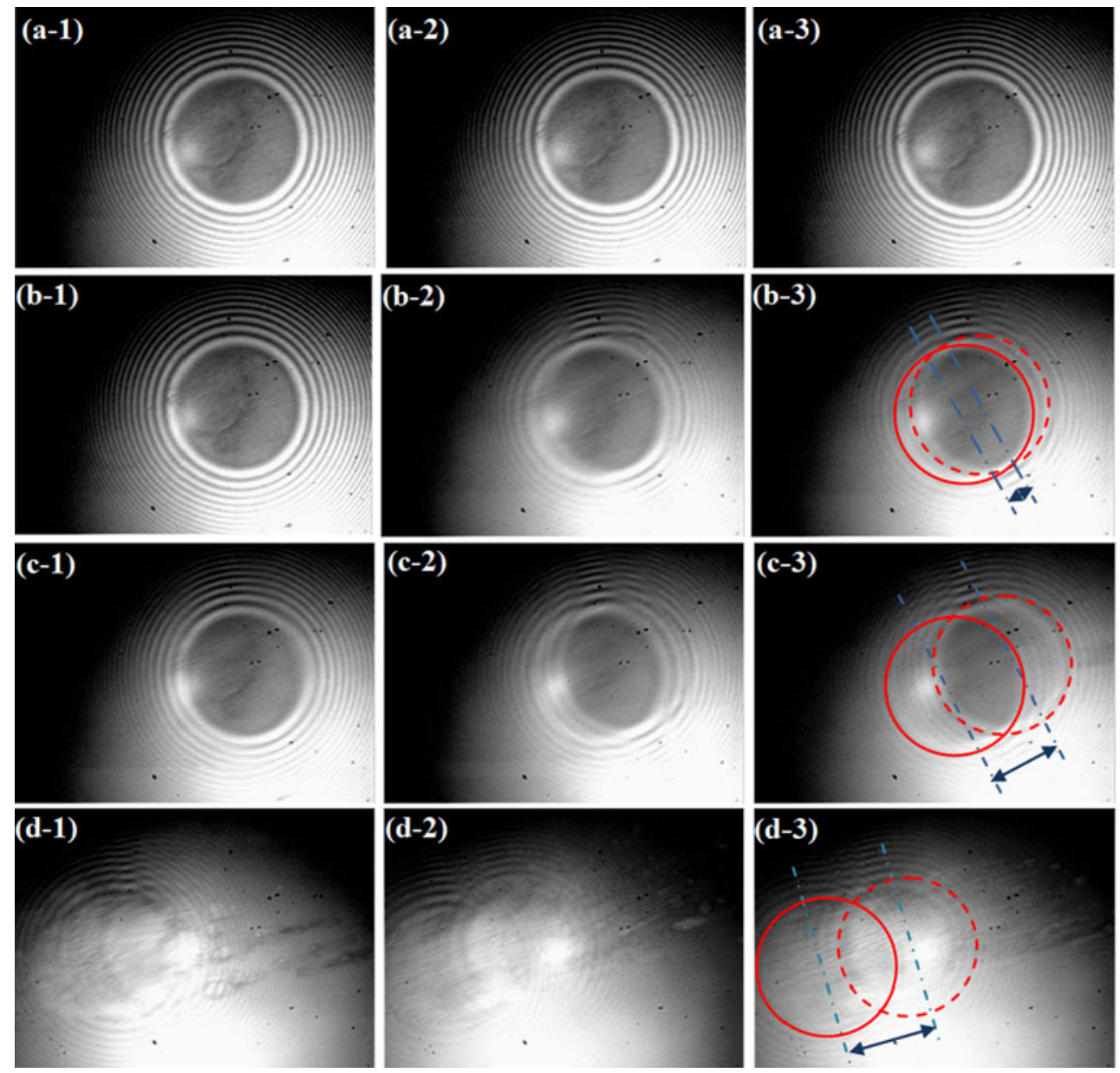
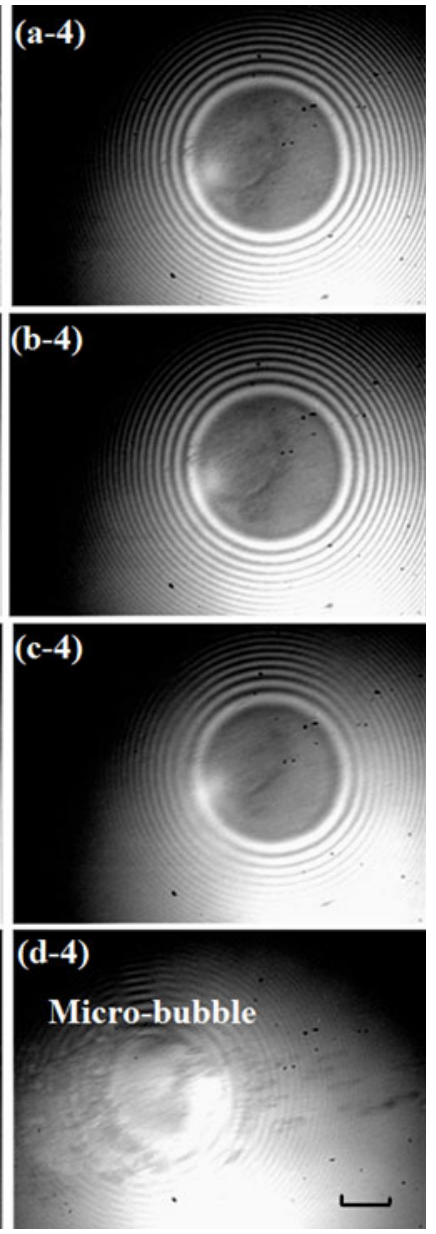

Fig. 2 Interference patterns of the grease lubricating film at different micro-oscillation amplitudes: a $0 \mu \mathrm{m}, \mathbf{b} 50 \mu \mathrm{m}, \mathbf{c} 150 \mu \mathrm{m}, \mathbf{d} 200 \mu \mathrm{m}$. Micro-oscillation frequency $20 \mathrm{~Hz}$ (Color figure online) 
micro-oscillation amplitude reached $150 \mu \mathrm{m}$ (Fig. 3d, red circles). In order to confirm the dependence of microbubble number on micro-oscillation amplitude in grease lubricating film when a micro-oscillation is applied, the microbubble numbers were measured directly from the digital pictures. To quantitatively investigate the microbubble, we extracted the microbubbles from the recorded images using standard image analysis techniques. The initial image is shown in Fig. 4a. The digital images analyzed using ImageJ2x software are shown in Fig. 4b, c.

The relationship between microbubble number and micro-oscillation amplitude is summarized in Fig. 5 where it can be seen that the microbubble behavior in the grease lubricating film is characterized by a bubble number of about $0,7,9$ and 14 for a micro-oscillation amplitude of $10,50,110$, and $150 \mu \mathrm{m}$, respectively. A slight increase in bubble number can be observed with larger micro-oscillation amplitude. When a micro-oscillation is applied onto a grease lubrication film, the critical amplitude is defined as the amplitude at which microbubbles begin to emerge. It is clear that the critical amplitude was around $10 \mu \mathrm{m}$ under our working conditions. Therefore, our results demonstrate that the microbubble emerging behavior in the grease lubricating film is sensitive to variations in micro-oscillation amplitude and relatively controllable.

\subsection{Effect of Micro-Oscillation Frequency} on Microbubble Behavior

In order to confirm the dependence of microbubble behavior on frequency when a micro-oscillation is applied, we applied different micro-oscillation frequencies while maintaining the micro-oscillation amplitude at $50 \mu \mathrm{m}$. Figure 6 shows the real-time interference patterns. The number of the microbubbles increased with increasing micro-oscillation frequency (Fig. 6a-d) up to a frequency of $200 \mathrm{~Hz}$; at $\geq 200 \mathrm{~Hz}$, the number of microbubbles decreased with the frequency, and at a frequency of $250 \mathrm{~Hz}$, the microbubble had disappeared (Fig. 6f). It is important to point out that microbubbles are generated. In order to extract quantitative information, microbubble number was measured directly from the digital pictures in Fig. 7. The relationship between microbubble number and micro-oscillation frequency is summarized in Fig. 8 which shows that the microbubble behavior in region 1 is characterized by a bubble number of approximately eight, 14 , and 20 for the micro-oscillation frequency of 50,100, and $150 \mathrm{~Hz}$, respectively. In contrast, microbubble behavior in the region 2 is characterized by a bubble number of approximately 20 , six, and one for the micro-oscillation frequency of 150,200 , and $250 \mathrm{~Hz}$, respectively. Microbubble number increased with micro-oscillation frequency,
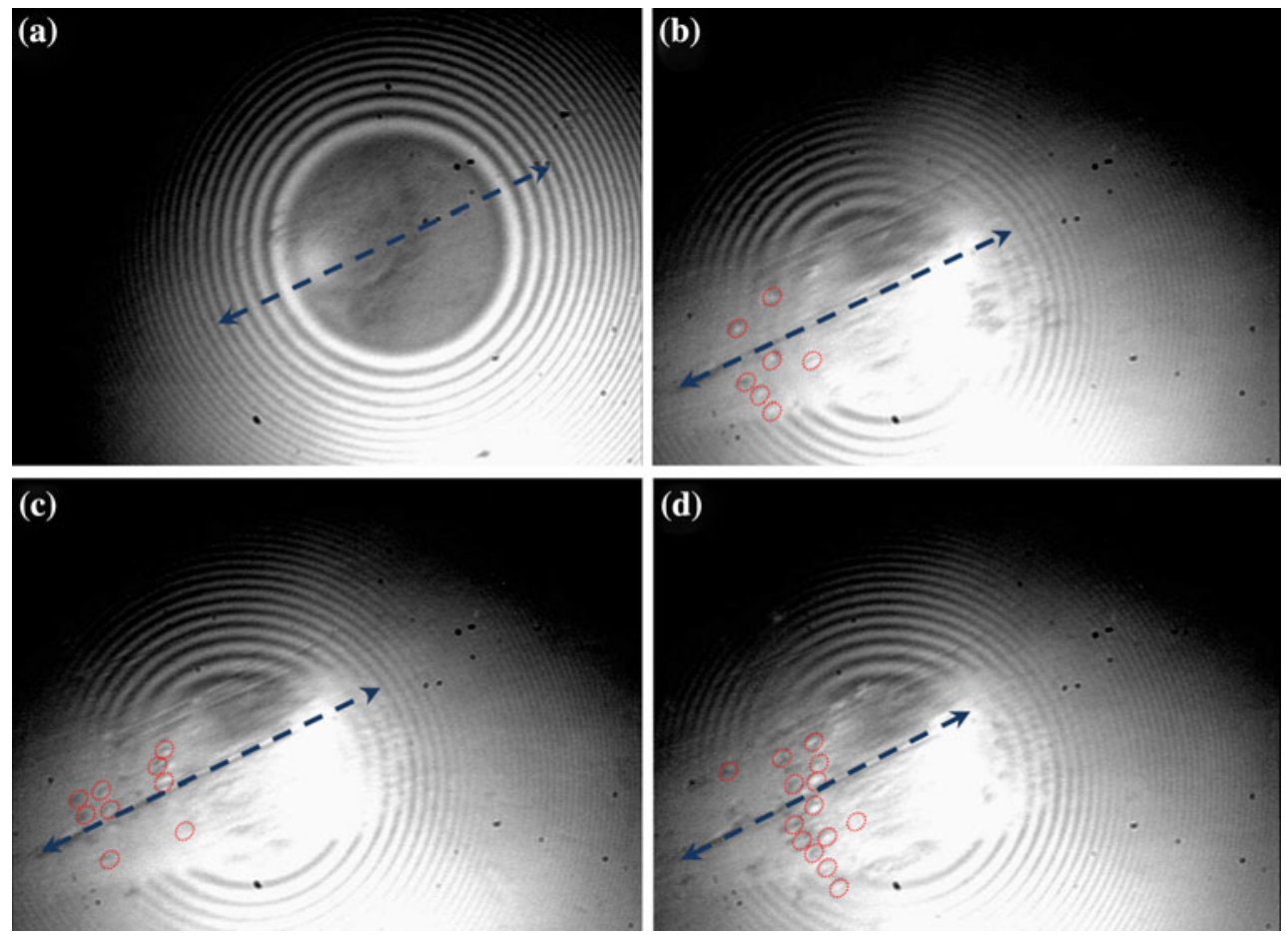

Fig. 3 Interference patterns of the grease lubricating film at different micro-oscillation amplitudes: a $10 \mu \mathrm{m}, \mathbf{b} 50 \mu \mathrm{m}, \mathbf{c} 110 \mu \mathrm{m}$, d $150 \mu \mathrm{m}$. micro-oscillation frequency: $50 \mathrm{~Hz}$ (Color figure online) 

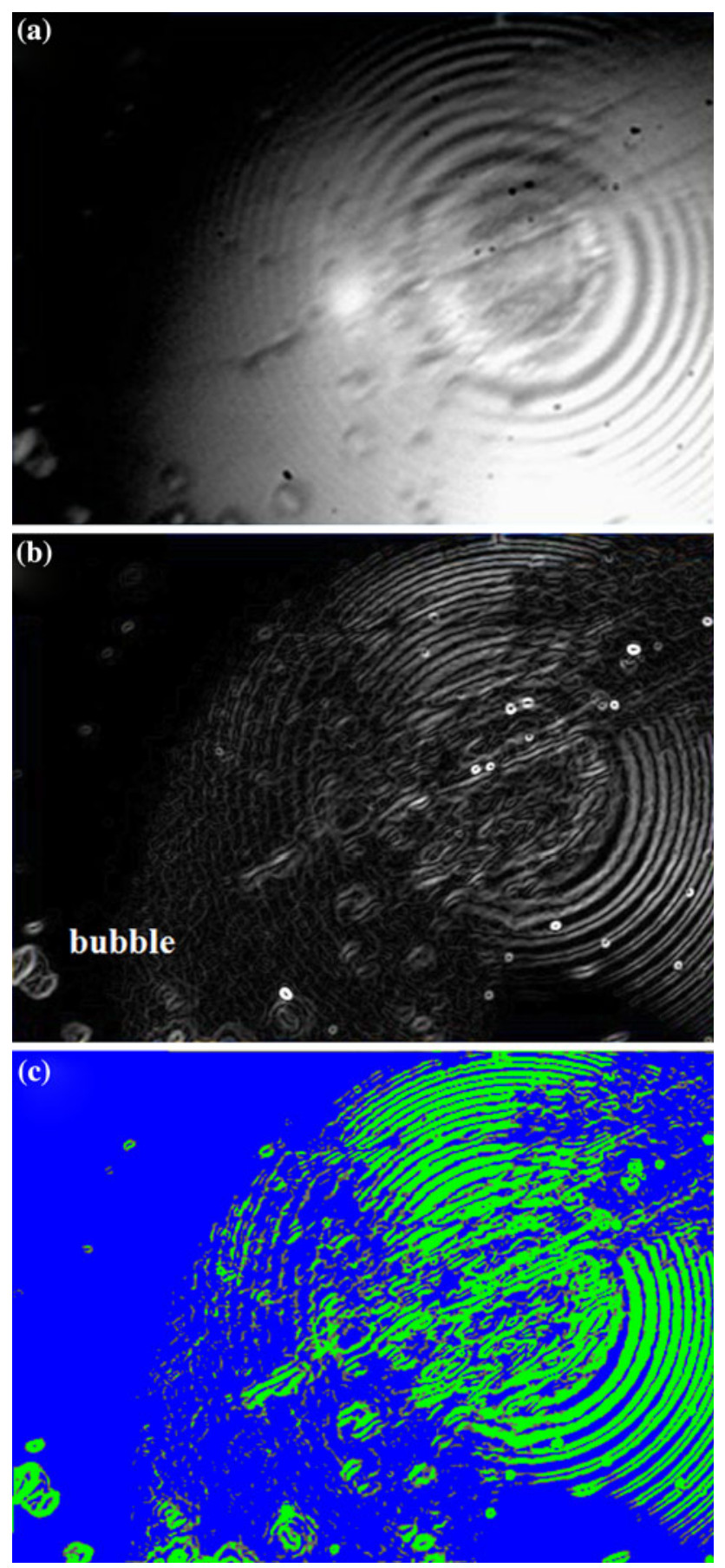

Fig. 4 Process of image treatment: a initial image, $\mathbf{b}$ binarized digital image, $\mathbf{c}$ colored digital image (Color figure online)

i.e., in region 1 in Fig. 8, when the micro-oscillation frequency was lower than the critical value of $150 \mathrm{~Hz}$, and decreased with micro-oscillation frequency, i.e., region 2 in Fig. 8, when the micro-oscillation frequency was higher than the critical value $150 \mathrm{~Hz}$. This result suggests that microbubble behavior in the grease lubricating film induced by micro-oscillation is relatively strongly dependent on frequency.

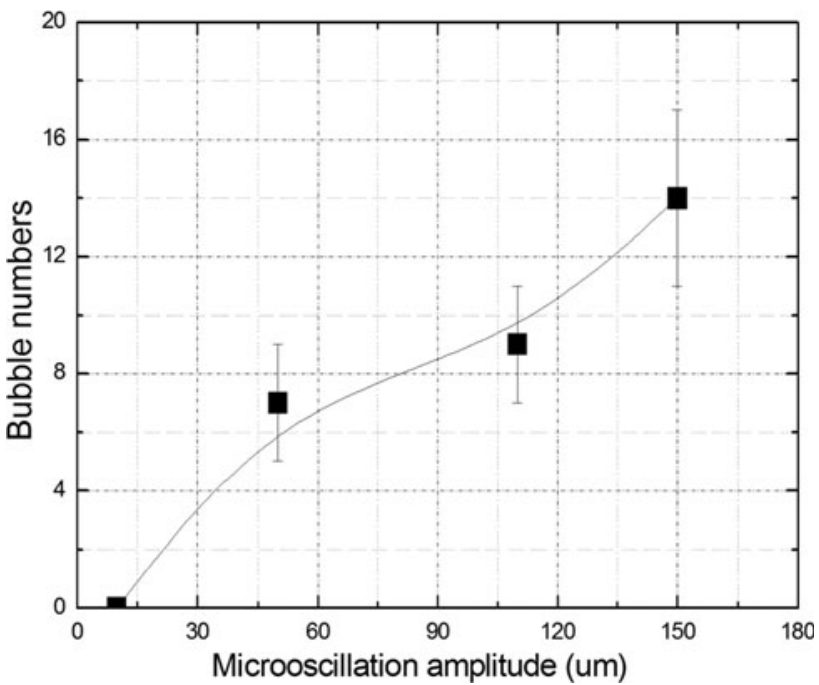

Fig. 5 Bubble number as a function of micro-oscillation amplitude. Micro-oscillation frequency: $50 \mathrm{~Hz}$

\section{Discussion}

It is important to know the mechanism by which microoscillation induces the emergence of microbubbles grease lubricating film. In fact, microbubbles are formed in grease lubricating film by cavitation [17-21]. Cavitation is defined as the process of nucleation in a liquid when the pressure falls below the vapor pressure [22]. In general, there are two forms of cavitation: gaseous and vaporous cavitation [22]. Gaseous cavitation, where gas (air) cavities may arise in a lubricant film whenever subambient pressures occur, and vaporous cavitation, which develops where the pressure in a lubricant film falls to its vapor pressure, both give rise to boiling of the lubricant at local ambient temperature. In Fig. 9 is a schematic diagram of microbubble formation in grease lubricating film induced by micro-oscillation. Cavitation depends upon the presence of gas nuclei. It is well known that lubricating grease is a complex system in which a pre-existing gas phase is absence, as shown in Fig. 9a. During micro-oscillation, cavitation bubbles expand as the contact moves away, as shown in Fig. 9b, c. Microbubbles grow on the nucleated surface until a critical microbubble diameter is reached, at which point they detach in a direction away from the surface and move in the direction of an area of lower pressure, i.e., they move away from the central region. When the contact region moves toward the bubbles, as shown in Fig. 9d, the bubbles shrink.

\subsection{Process of Microbubble Growth}

Microbubbles emerge at the edge of the contact area when a specific load is applied. Based on classical Hertz theory, a rapid decrease in pressure is present at the edge area [23]. 

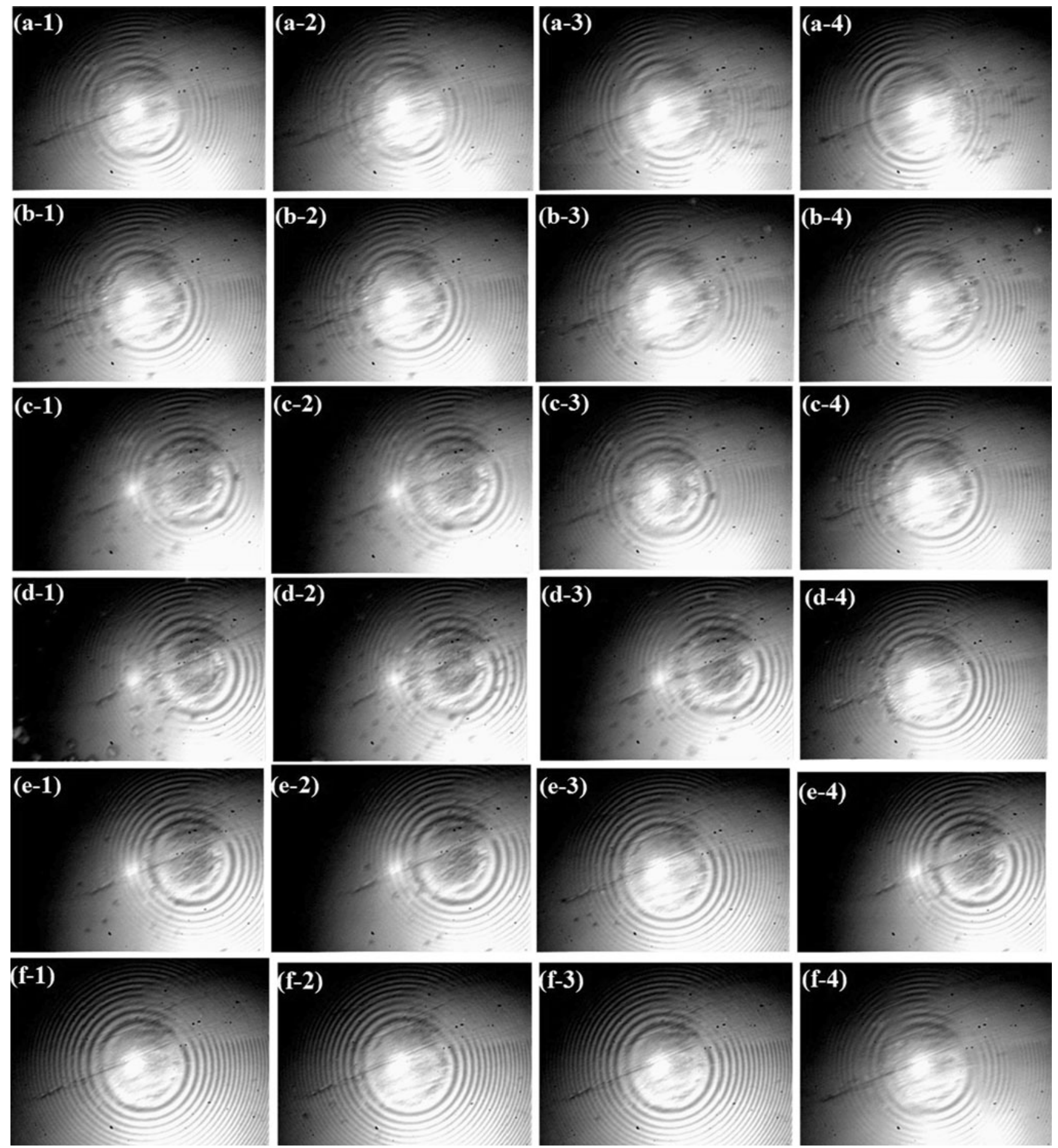

Fig. 6 Interference patterns of the grease lubricating film at different micro-oscillation frequencies: a $50 \mathrm{~Hz}, \mathbf{b} 80 \mathrm{~Hz}, \mathbf{c} 100 \mathrm{~Hz}, \mathbf{d} 150 \mathrm{~Hz}$, e $200 \mathrm{~Hz}, \mathbf{f} 250 \mathrm{~Hz}$. Micro-oscillation amplitude: $50 \mu \mathrm{m}$

At the beginning of microbubble growth, the average expansion velocity $V_{\mathrm{b}}$ of the microbubble increases with $\mathrm{d} P / \mathrm{d} t_{\mathrm{m}}$, where $P$ is the contact pressure and $t_{\mathrm{m}}$ is the time of microbubble growth. The micro-oscillation velocity $V_{\mathrm{m}}$ is defined by

$V_{\mathrm{m}}=L_{\mathrm{m}} f_{\mathrm{m}}$ where $L_{\mathrm{m}}$ is the micro-oscillation amplitude and $f_{\mathrm{m}}$ is the micro-oscillation frequency. $\mathrm{d} P / \mathrm{d} t_{\mathrm{m}}$ can be estimated as $\mathrm{d} P / \mathrm{d} t_{\mathrm{m}} \sim V_{\mathrm{m}}$. Hence, the microbubble average expansion velocity $V_{\mathrm{b}}$ increases with $V_{\mathrm{m}}$ at the beginning of microbubble growth. This indicates that microbubble number increases with $V_{\mathrm{m}}$. 

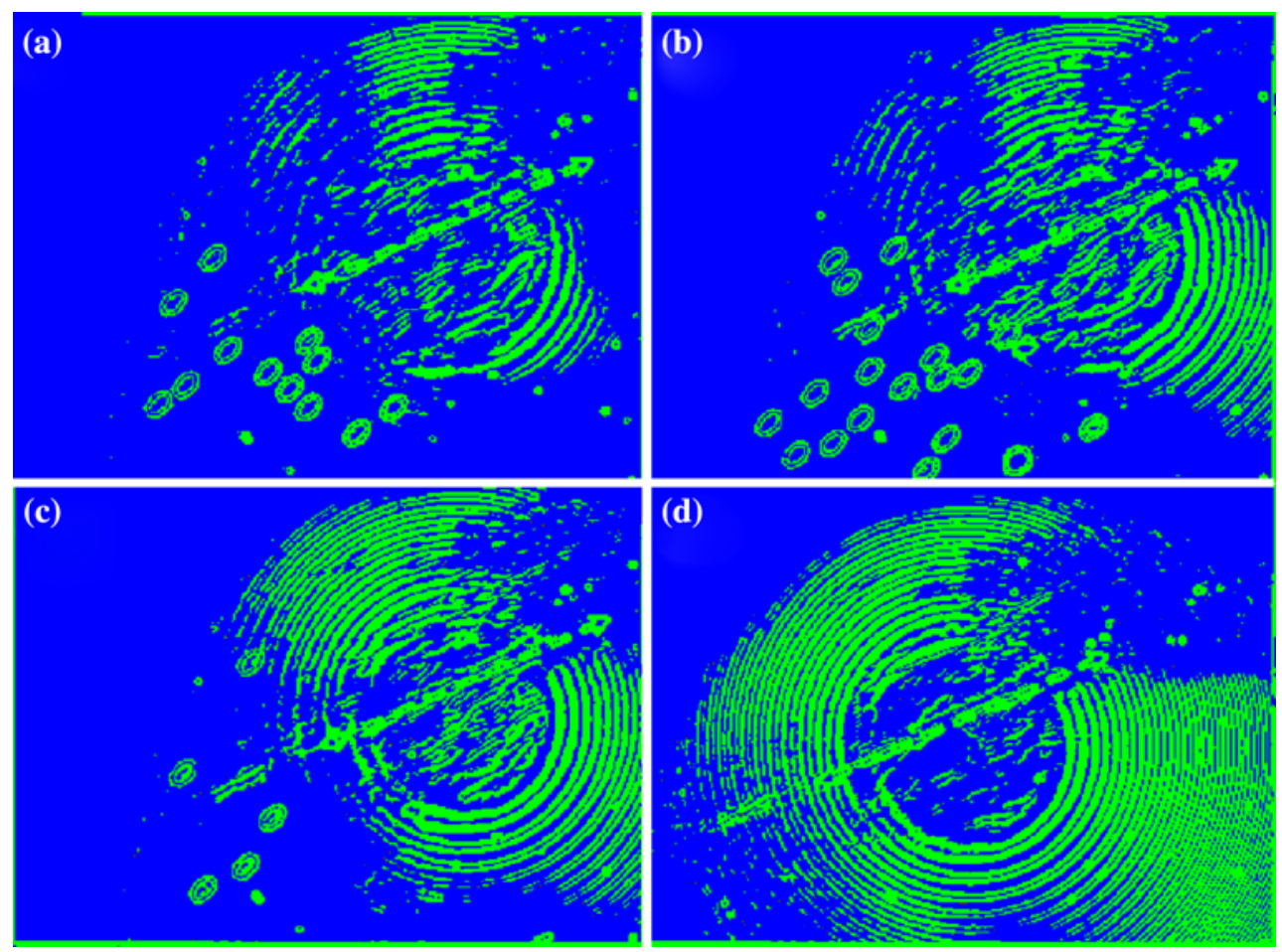

Fig. 7 Colored images of the grease lubricating film at different micro-oscillation frequencies: a $50 \mathrm{~Hz}, \mathbf{b} 150 \mathrm{~Hz}, \mathbf{c} 200 \mathrm{~Hz}, \mathbf{d} 250 \mathrm{~Hz}$. Microoscillation amplitude: $50 \mu \mathrm{m}$ (Color figure online)

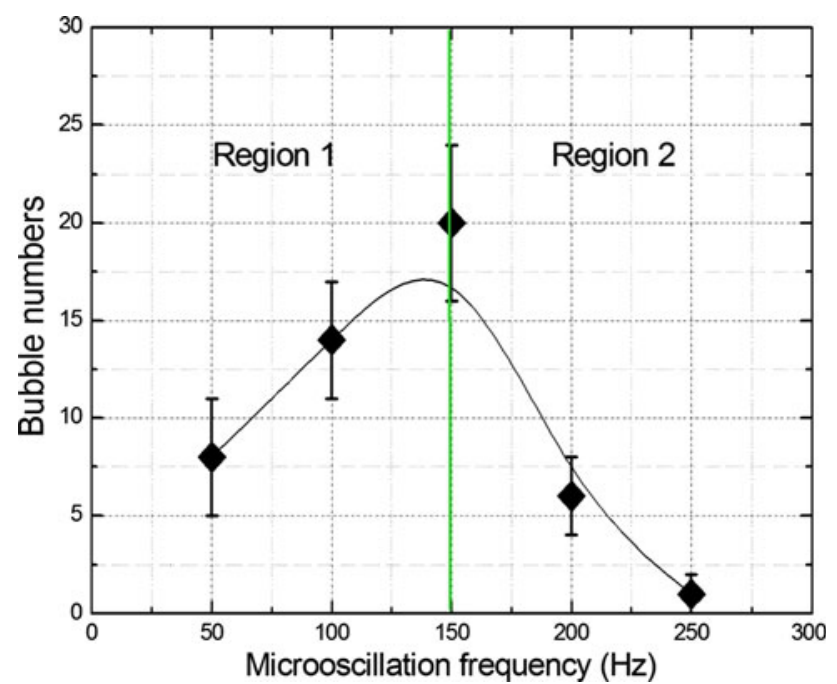

Fig. 8 Bubble number as a function of micro-oscillation frequency. Micro-oscillation amplitude: $50 \mu \mathrm{m}$

\subsection{Process of Microbubble Detachment}

Microbubbles grow on the nucleated surface until a critical bubble diameter is reached at which point they detach in a direction away from the surface. Several important forces contribute to the detachment process of a microbubble. The force $F_{\text {drive }}$ drives the bubbles to move away from the contact region just after the detachment in the direction parallel to the disc surface [23]:

$F_{\text {drive }}=\frac{3 \alpha \pi W d \Delta r}{2 r^{2}}$

where $W$ is the externally applied load, $r$ is the contact radius, $\Delta r$ is the length of the small region outside the contact area where bubbles tend to emerge, $d$ is the diameter of the spherical bubble at the growth stage, and $\alpha=P_{\mathrm{r}} / P_{\mathrm{m}}\left(P_{\mathrm{r}}:\right.$ a residual pressure at the contact edge, $P_{\mathrm{m}}$ : the maximum contact pressure). When the detached bubbles move away from the pressure field near the contact region, their motion will be controlled merely by the drag force $F_{\mathrm{d}}$ in the liquid. It is important to point out that for convenience the bubble shape is assumed to be ideally spherical in the analysis of bubble motion. The drag force in the viscous fluid can be described as [24]:

$F_{\mathrm{d}}=-6 \pi \eta \mathrm{d} v$

The motion of a spherical bubble in a viscous liquid is induced by a balance between the acceleration of the added mass of the liquid and the Levich drag [25]. When the bubble detaches from the nucleation site and begins to move, its movement is dominated mainly by the drag force in the liquid near the contact region. The power of this force [left part of Eq. (4)] should be equal to the rate of the 
(a)
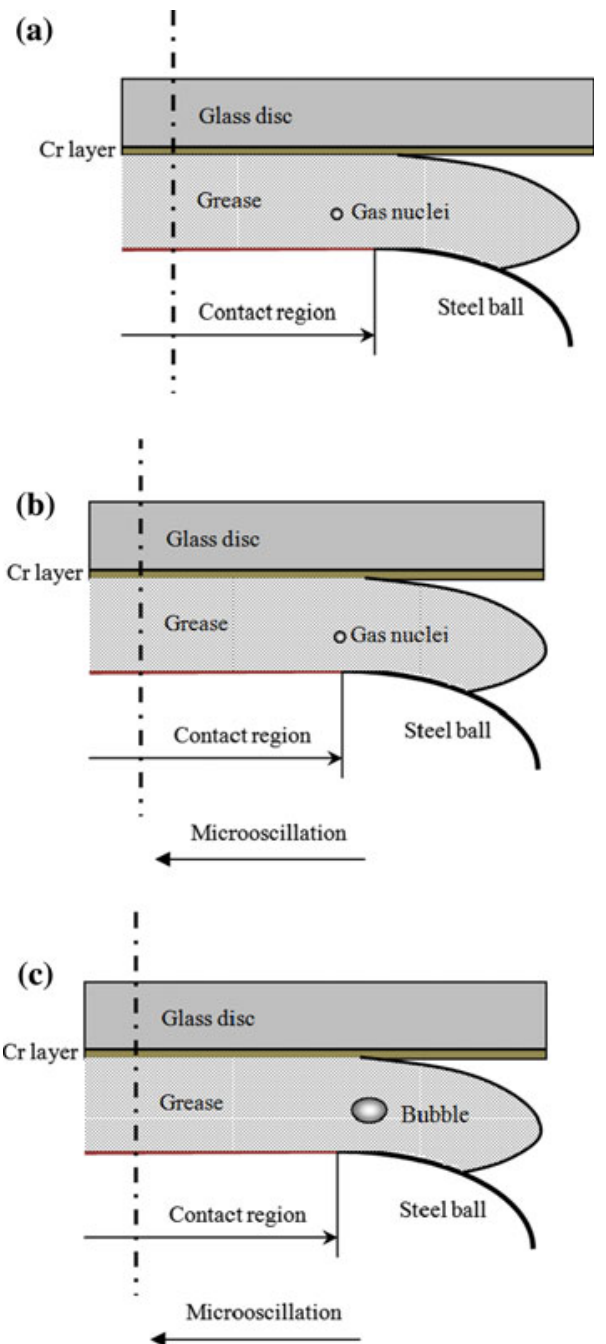

(d)

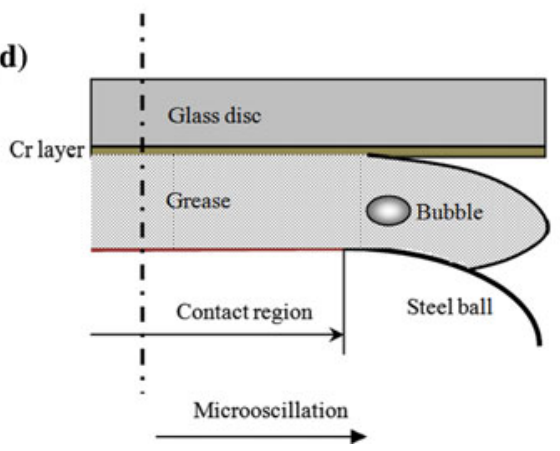

Fig. 9 Schematic diagram of microbubble formation induced by micro-oscillation in grease lubricating film

change in kinetic energy of the liquid and the bubble [right part of Eq. (4)] [26]:

$\left(F_{\text {drive }}+F_{\mathrm{d}}\right) v=(m+\Delta m) v \frac{\mathrm{d} v}{\mathrm{~d} t}$

where $t$ is the time of microbubble detachment, and $m$ and $\Delta m$ are the mass of the bubble and the added mass, respectively. For a spherical bubble, $m$ can be assumed to be zero and $\Delta m$ can be expressed as

$\Delta m=\frac{1}{12} \pi d^{3} \rho$

Substituting Eqs. (2), (3) and (5) into Eq. (4), we obtain

$\left(F_{\text {drive }}-6 \pi \eta \mathrm{d} v\right) v=\frac{1}{12} \pi d^{3} \rho v \frac{\mathrm{d} v}{\mathrm{~d} t}$

The force due to the pressure difference around the contact region acting on the bubble is supposed to disappear suddenly because $\Delta r$ is estimated to be $\sim 1 \mu \mathrm{m}$ or even less. In this case Eq. (6) simplifies to

$-6 \pi \eta \mathrm{d} v=\frac{1}{12} \pi d^{3} \rho \frac{\mathrm{d} v}{\mathrm{~d} t}$

Suppose the velocity of the bubble at the moment when the pressure difference force vanishes is $v_{0}$; then, the velocity $v_{1}$ of the microbubble beyond the scope of the pressure difference force can be derived from Eq. (7):

$v_{1}=v_{0} e^{-72 \eta t / \rho d^{2}}$

The detachment time of the microbubbles decreases with the micro-oscillation frequency. Therefore, the velocity $v_{1}$ of the microbubble increases with the micro-oscillation frequency according to Eq. (8). The velocity $v_{1}$ is actually the velocity needed by the microbubble to detach from the contact area. It indicates that the microbubble number decreases with $f_{\mathrm{m}}$.

The effect of micro-oscillation parameters on microbubble behavior need to be comprehensively analyzed together with the growth and detachment of the microbubbles. When the micro-oscillation frequency $f_{\mathrm{m}}$ is a constant value: (1) in the process of microbubble growth, $V_{\mathrm{m}}$ increases with the micro-oscillation amplitude and the microbubble number increases with the micro-oscillation amplitude; (2) in the process of microbubble detachment, the microbubble number cannot be affected by microoscillation amplitude. Hence, the microbubble number increases with $L_{\mathrm{m}}$, as shown in Fig. 5. When the microoscillation amplitude $L_{\mathrm{m}}$ is a constant value: (1) in the process of microbubble growth, $V_{\mathrm{m}}$ increases with the micro-oscillation frequency and the microbubble number increases with the micro-oscillation frequency; (2) in the process of microbubble detachment, the microbubble number decreases with the micro-oscillation frequency. Therefore, in our comprehensive analysis of the growth and detachment of the microbubbles, the microbubble number increased with $f_{\mathrm{m}}$, i.e., the region 1 in Fig. 8 , when $f_{\mathrm{m}}$ was lower than the critical value, and the microbubble number decreased with $f_{\mathrm{m}}$, i.e., region 2 in Fig. 8, when $f_{\mathrm{m}}$ was higher than the critical value. 


\section{Conclusions}

In summary, a microbubble phenomenon in the grease lubricating film induced by micro-oscillation has been observed with an interferometer. Experimental results indicate that when micro-oscillation frequency is a constant value, microbubble number increases with the microoscillation amplitude. We found that when the microoscillation amplitude is a constant value, microbubble number increases with the increasing micro-oscillation frequency when the micro-oscillation frequency is lower than the critical value and that microbubble number decreases with increasing micro-oscillation frequency when the micro-oscillation frequency is higher than the critical value. The microbubble phenomenon has been discussed in the framework of a theoretical analysis. The present study might provide some complementary insights into grease lubrication and the worn behavior of reciprocating engineering components.

Acknowledgments The work is financially supported by the International Science and Technology Cooperation Project, the National Natural Science Foundation of China (Grant No. 51175514), and the $\mathrm{PhD}$ Programs Foundation of Ministry of Education of China (Grant No. 20100007120010).

Open Access This article is distributed under the terms of the Creative Commons Attribution License which permits any use, distribution, and reproduction in any medium, provided the original author(s) and the source are credited.

\section{References}

1. Jonkisz, W., Krzemiski-Freda, H.: Pressure distribution and shape of an elastohydrodynamic grease film. Wear 55, 81-89 (1979)

2. Bordenet, L., Dalmaz, G., Chaomleffel, J.-P., Vergne, F.: A study of grease film thickness in elastorheodynamic rolling point contacts. Lubr. Sci. 2, 273-284 (1990)

3. Åström, H., Isaksson, O., Höglund, E.: Video recordings of an EHL point contact lubricated with grease. Tribol. Int. 24, 179-184 (1991)

4. Cann, P.M., Williamson, B.P., Coy, R.C., Spikes, H.A.: The behavior of greases in elastohydrodynamic contacts. J. Phys. D Appl. Phys. 25, A124-A132 (1992)

5. Cann, P., Lubrecht, A.A.: An analysis of the mechanisms of grease lubrication in rolling element bearings. Lubr. Sci. 11, 227-245 (1999)

6. Cann, P.M.: Starved grease lubrication of rolling contacts. Tribol. Trans. 42, 867-873 (1999)
7. Hurley, S., Cann, P.M., Spikes, H.A.: Lubrication and reflow properties of thermally aged greases. Tribol. Trans. 43, 221-228 (2000)

8. Cann, P.M., Doner, J.P., Webster, M.N., Wikstrom, V.: Grease degradation in rolling element bearing. Tribol. Trans. 44, 399-404 (2001)

9. Cann, P.M.: Grease degradation in a bearing simulation device. Tribol. Int. 39, 1698-1706 (2006)

10. Larsson, P.O., Larsson, R., Jolkin, A., Marklund, O.: Pressure fluctuations as grease soaps pass through an EHL contact. Tribol. Int. 33, 211-216 (2000)

11. Miettinen, J., Andersson, P., Wikström, V.: Analysis of grease lubrication of rolling bearings using acoustic emission measurement. Proc. Instn. Mech. Engrs., Part J. J. Eng. Tribol. 215, 535-544 (2001)

12. Miettinen, J., Andersson, P.: Acoustic emission of rolling bearings lubricated with contaminated grease. Tribol. Int. 33, 777-787 (2000)

13. Mota, V., Ferreira, L.A.: Influence of grease composition on rolling contact wear: experimental study. Tribol. Int. 42, 569-574 (2009)

14. Cousseau, T., Björling, M., Graça, B., Campos, A., Seabra, J., Larsson, R.: Film thickness in aball-on-disc contact lubricated with greases, bleed oils and base oils. Tribol. Int. 53, 53-60 (2012)

15. Li, G., Zhang, C.H., Luo, J.B., Liu, S.H., Xie, G.X., Lu, X.C.: Film-forming characteristics of grease in point contact under swaying motions. Tribol. Lett. 35, 57-65 (2009)

16. Li, G., Zhang, C.H., Xu, H.Y., Luo, J.B., Liu, S.H.: The film behaviors of grease in point contact during micro-oscillation. Tribol. Lett. 38, 259-266 (2010)

17. Lugt, P.M.: A review on grease lubrication in rolling bearings. Tribol. Trans. 52, 470-480 (2009)

18. Leonarda, B., Sadeghia, F., Cipraa, R.: Gaseous Cavitation and Wear in Lubricated Fretting Contacts. Tribol. Trans. 51, 351-360 (2008)

19. Leonarda, B., Sadeghi, F., Shinde, S., Mittelbach, M.: A novel modular fretting wear test rig. Wear 274-275, 313-325 (2012)

20. Zeidan, F.Y., Vancea, J.M.: Cavitation leading to a two phase fluid in a squeeze film damper. Tribol. Trans. 32, 100-104 (1989)

21. Zeidana, F.Y., Vancea, J.M.: Cavitation regimes in squeeze film dampers and their effect on the pressure distribution. Tribol. Trans. 33, 447-453 (1990)

22. Brennen, C.E.: Cavitation and bubble dynamics. Oxford University Press, Oxford (1995)

23. Xie, G.X., Luo, J.B., Liu, S.H., Guo, D., Li, G., Zhang, C.H.: Effect of liquid properties on the growth and motion characteristics of micro-bubbles induced by electric fields in confined liquid films. J. Phys. D Appl. Phys. 42, 115502 (2009)

24. Duhar, G., Riboux, G., Colin, C.: Vapour bubble growth and detachment at the wall of shear flow. Heat Mass Transfer 45, 847 (2009)

25. Joseph, D.D., Wang, J.: The dissipation approximation and viscous potential flow. J. Fluid Mech. 505, 365 (2004)

26. Joseph, D.D.: Potential flow of viscous fluids: historical notes. Int. J. Multiphas. Flow 32, 285 (2006) 